\title{
Validation Study of Behavior Problems Inventory-01 among Korean Children and Adolescents
}

\author{
Miji Choi', Yeni Kim¹, Ji-Jeong Ban², Samuel Suk-Hyun Hwang ${ }^{3}$, \\ Bung-Nyun $\mathrm{Kim}^{4}$, and Young-Hui Yang ${ }^{1}$ \\ ${ }^{1}$ Department of Child and Adolescent Psychiatry, National Center for Mental Health, Seoul, Korea \\ ${ }^{2}$ Department of Early Childhood Special Education, Korea Nazarene University, Cheonan, Korea \\ ${ }^{3}$ Department of Psychology, Chonnam National University, Gwangju, Korea \\ ${ }^{4}$ Department of Psychiatry, College of Medicine, Seoul National University, Seoul, Korea
}

\section{한국판 문제행동 평가도구(Behavior Problems Inventory-01) 표준화 연구}

\author{
최미지 ${ }^{1}$, 김예니 ${ }^{1}$, 반지정 ${ }^{2}$, 황석현 ${ }^{3}$, 김붕년 ${ }^{4}$, 양영희 $^{1}$ \\ 국립정신건강센터 소아청소년정신건강의학과, ${ }^{1}$ 나사렛대학교 유아특수교육과, ${ }^{2}$ 전남대학교 심리학과, ${ }^{3}$ 서울대학교 의과대학 정신건강의학교실
}

\begin{abstract}
Objectives: The purpose of this study was to examine the reliability and validity of the Korean version of the Behavior Problems Inventory (BPI-01) among children and adolescents aged between 3 and 18 .

Methods: The control group consisting of one hundred children and adolescents was recruited from schools and the patient group consisting of forty one children and adolescents with autism spectrum disorder were recruited from a hospital. We compared the measurements of both groups. To assess the concurrent validity of the BPI-01, we compared the problem behavior index of the Korean Scale of Independent Behavior-Revised (K-SIB-R) and, to assess the discriminant validity, we compared the Korean version of the Child Behavior Checklist (K-CBCL). The Cronbach's alpha of the BPI-01 was measured to assess its reliability. Correlation analyses between the BPI-01 and the other scale were carried out to examine the former's concurrent and discriminant validity.

Results: The patient group showed a significantly higher score for all three subscales of the BPI than the control group. The Cronbach's alpha was 0.92 for the total severity score of the BPI and ranged between 0.67-0.89 for each subscale in the patient group. All subscales of the BPI-01's, i.e., self injurious behavior, stereotyped behavior and aggressive/destructive behavior, were significantly correlated with the corresponding subscales of the K-SIB-R. The BPI-01 generally did not demonstrate any significant correlation with emotional items such as anxiety/depression in the K-CBCL. Especially, the BPI-01's stereotyped behavior subscale showed little correlation with externalizing behaviors such as social problems and aggressive behaviors.

Conclusion: This study found that the Korean version of BPI-01 is a reliable and valid behavior rating instrument for problem behavior in developmental disabilities among children and adolescents.
\end{abstract}

Key Words: Problem behavior; Autism spectrum disorder; BPI.

Received: December 30, 2016 / Revision: April 16, 2017 / Accepted: April 24, 2017

Address for correspondence: Young-Hui Yang, Department of Child and Adolescent Psychiatry, National Center for Mental Health, 127 Yongmasan-ro, Gwangjin-gu, Seoul 04933, Korea

Tel: +82-2-2204-0118, Fax: +82-2-2204-0389, E-mail: yhyang12@korea.kr

\section{서 론}

넓은 의미의 발달 장애는 지적 장애와 자폐 스펙트럼 장애 를 지칭하며, 우리나라의 등록 장애인 중 발달 장애 아동은 2015년 통계를 기준으로 58065명이다. 그중 자폐아동의 경우

This is an Open Access article distributed under the terms of the Creative Commons Attribution Non-Commercial License (http://creativecommons.org/licenses/by-nc/4.0) which permits unrestricted non-commercial use, distribution, and reproduction in any medium, provided the original work is properly cited.
2007년 10526명에서 2015년 13653명으로, 연간 400여 명씩 증가하고 있는 추세이다. ${ }^{1)}$ 자폐 스펙트럼 장애의 유병률은 우 리나라뿐만 아니라 전 세계적으로 증가 추세에 있는데, 이는 자폐 스펙트럼 장애에 대한 대중의 인식 증진, 더 어린 나이에 진단되는 경향, 자폐 스펙트럼 장애 진단 기준의 폭이 넓어지 는 데에서 기인하는 것으로 보인다. ${ }^{2)}$ 따라서 현재 정확한 진단 을 받지 못했거나 장애등록을 하지 않은 인구를 포함하면 앞 으로 발달 장애 아동의 수는 더욱 증가할 것으로 예상된다. ${ }^{3)}$ 
행동 문제는 발달 장애를 가진 아동의 32 56\%에서 동반되 는데,5) 핵심증상인 적절한 사회적 소통방법의 결핍과 상동 행동뿐만 아니라, 강박적인 특성, 자극 과민성, 동반 질환 등 에 의해서도 발생할 수 있다. 문제행동은 자해 행동, 상동 행 동, 공격성이나 파괴 행동으로 나타날 수 있는데, ${ }^{6}$ 짜증이나 분 노 발작에서부터 물건을 던지고 부수는 행동, 자신이나 타인 을 물고 때리는 행동까지 보일 수 있다. 또한, 문제행동은 그 양상, 강도, 빈도, 기간이 다양할 뿐만 아니라 많은 경우 성인기

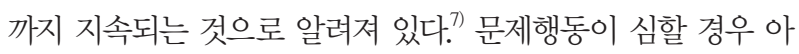
동은 자신 및 다른 사람에게 해를 끼칠 수 있고, 이런 경우 아 동은 교육, 사회 활동 등에 참여를 제한 받게 되어 새로운 발 달 기술 습득과 또래와의 사회적 형성을 방해 받을 수 있 다. ${ }^{899}$ 이렇게 만성적이고 심각한 문제행동은 단순히 신체 손 상의 위험을 높일 뿐만 아니라, 일생에 걸쳐 아동의 사회 참여 에 부정적인 결과를 낳게 하고, 입원, 거주 시설로의 배치 등 사회적 고립을 야기할 수 있다. ${ }^{10)}$ 발달 장애 아동의 문제행동 은 비단 장애 아동 자신뿐 아니라 가족에게도 지대한 영향을 주는데, 문제행동은 주 양육자를 포함한 가족 구성원에게 상 해를 입히거나 가족의 일상을 심각하게 방해함으로써 가족 의 신체적, 정신적 건강과 전반적인 삶의 질을 위협하며, 이러 한 상태는 오랜 기간에 걸쳐 계속될 수 있다. ${ }^{11,12)}$ 생애 주기 전 반에 걸쳐 지속되는 발달 장애와 문제행동의 만성적인 특성 과, 환자 본인과 가족이 받는 심적, 물질적 부담을 고려하면 발달 장애 아동의 문제행동이 야기하는 사회경제적 비용이 상당함을 예상할 수 있다.

이와 같은 발달 장애 문제행동의 심각성에도 불구하고, 사 회적 서비스 및 치료 기반의 부족, 보호자의 인식부족, 경제적 부담 등의 다양한 이유로 발달 장애인 문제행동의 평가와 중 재에 대한 요구가 적절히 충족되지 못한 경우가 많다. ${ }^{13)}$ 성인 기 발달 장애인의 경우, 시설 부족으로 인해 사회복지서비스 를 이용하는 경우가 $5 \%$ 내외에 불과하였다. ${ }^{14)}$ 한편, 중재 서비 스가 제공되는 경우에도 그 과정에서 대상자의 요구가 충분 히 충족되지 못하는 경우가 많았다. 발달 장애 아동의 경우, 문제행동이 잦은 빈도에 비해 적절히 평가되고 중재되지 못 하는 경향이 있어, 부모와 교사들의 문제행동 대처를 위한 전 문적인 지원 필요성에 대한 요구도가 높은 것으로 나타났 다. ${ }^{15)}$ 발달 장애의 경우 적절한 시기의 중재가 특히 중요한데, 정서, 행동적인 문제를 제때 확인하지 못하면, 중재에 대한 아 동의 반응을 약화시켜 주요 치료 목표가 되는 사회적 의사소 통 증진 등의 조기 중재 효과가 제대로 이루어지기 어려운 면 이 있다.) 이러한 조기 중재 실패는 지속되는 행동 문제를 야기 하여 아동과 가족의 스트레스를 가중시키고, 기능적 장애를 악화시키는 결과로 이끌 수 있다. ${ }^{8)}$ 중재 현장에서 적절한 치료
적 개입 위해서는 우선적으로 신뢰할 수 있고 타당도 있는 문제 행동 평가도구가 필요하며, 이는 치료 효과 검증과 성공적인 문 제행동 예방에 중요한 요소이다.

현재 국내에서 개발된 문제행동 평가도구가 전무하며 이에 대한 연구가 미비한 실정이다. 따라서, 우리나라 실정에 적합 한 문제행동 평가도구의 표준화가 필요하며, 평가도구 사용 방 법 및 결과 해석과 관련된 전문가 지침서 개발이 필요하다. 현 재 활발하게 사용되고 있는 문제행동 측정 검사는 이상 행동 체크리스트(Aberrant Behavior Checklist, $\mathrm{ABC}$ ), 아동 행동 평가척도(Child Behavior Checklist, $\mathrm{CBCL}$ ), 문제행동 평가 도구(Behavior Problems Inventory-01, BPI-01) 등이 있다. 그중 $\mathrm{ABC}$ 와 $\mathrm{CBCL}$ 은 행동 문제의 폭넓은 영역을 포괄적으 로 측정하는 검사이다. 반면, $\mathrm{BPI}-01$ 은 문제행동 중 공격성, 파괴행동, 자해와 같은 영역에 초점을 맞춘 측정도구이기 때 문에, 심한 문제행동을 측정하는데 더 유리한 검사이며, 특히 지적 장애나 자폐 스펙트럼 장애 환자에 적용하여 임상에서 문제행동의 위험성을 판단하거나 치료효과를 판정하기에 적 합한 도구이다. ${ }^{10)}$ 한국판 문제행동 평가도구(BPI-01)를 표준 화한 이전 연구가 있으나, 이는 병원에 내원하는 임상군이 아 니었고 지적 장애 성인을 대상으로 진행되어, 임상군의 조기 발견과 중재 효과 판정의 적합성에 한계가 있을 수 있었다. ${ }^{17}$ 따라서, 본 연구는 정상군과 병원을 방문하는 자폐 스펙트럼 장애 아동 모두를 대상으로 하여 BPI-01의 신뢰도와 타당도 를 검증해 보고자 한다.

\section{방 법}

\section{대 상}

환자군은 국립정신건강센터 소아청소년 정신건강의학과를 내원하여 자폐 스펙트럼 장애 진단을 받은 만 3세부터 18세 미만의 환자 중 보호자의 자유의사로 연구에 참여하기 원하 는 자 61명을 선정하였고, 중도 탈락자를 제외하면 41명이 최 종 연구에 포함되었다. 정상 대조군은 초등학교, 중학교, 고등 학교에 연구에 대해 알린 후 지원할 학급 혹은 기관을 모집하 여 3 18세 미만의 남녀 100명으로 선정하였다. 정상 대조군 의 설명문은 가정 통신문 형식으로 보호자에게 전달하여 교 사가 일괄 회수하였다. 연구 대상자에게 서면 연구 동의를 받 았으며, 설문지는 연구원들이 지원 학급 혹은 기관이 소재한 현장으로 방문하여 설명하였고, 작성된 설문지는 연구원이 직 접 수거하였다. 조절되지 않은 간질 및 기타 의학적 질환이 있 는 경우, 보호자가 임상 연구에 동의하지 않는 경우 등 충분한 정보를 제공하기 어려운 경우는 제외하였다. 본 연구는 국립정 신건강센터의 임상시험심사위원회(Institutional Review Board) 
의 승인을 받아 진행되었다(IRB No. 2014-31).

\section{평가도구}

한국판 문제행동 평가도구(Behavior Problems Inventory-01, BPI-01)

BPI-01은 정보제공자 중심의 행동 평가도구로 지적 장애를 가진 개인의 자해 행동, 상동 행동, 공격적/파괴적 행동 유무 와 그 심각도 및 빈도를 평가하기 위해 개발되었다. 방수영 등 이 표준화한 한국판 $\mathrm{BPI}-01^{16,18)}$ 은 수년에 걸쳐 여러 척도를 표 준화한 경험이 풍부한 연구진과, 원저자와의 의사소통, 번역 및 역번역이 가능한 석박사급의 연구원이, 후보 척도인 BPI-01에 대하여 원저자의 허락을 받아 번안되었다.

본 검사 도구는 자해항목 14 개, 상동 행동 항목 24 개, 공격 적/파괴적 행동 항목 11 개로 구성되어 있다. 이에 더하여 각 범 주는 기타 항목을 1 개씩 추가하여 기입할 수 있다. 항목들은 빈 도 5 점 척도 $(0=$ 없음, $1=$ 매월, $2=$ 매주, $3=$ 매일, $4=$ 매시간 $)$ 심각 도 5 점 척도 $(0=$ 없음, $1=$ 경도, $2=$ 중도, $3=$ 중고도, $4=$ 고도 $)$ 로 평 가하도록 되어 있다. ${ }^{18)}$

\section{한국판 적응행동검사(Korean Scales of Independent}

Behavior-Revised, $\mathrm{K}-\mathrm{SIB}-\mathrm{R}$ )

한국판 적응행동검사는 미국의 적응행동검사(Scales of Independent Behavior-Revised, 1996)를 국내에서 표준화한 검사도구이다. ${ }^{19)}$ 본 검사 도구는 만 5 12세까지의 일반 아동 을 남녀별로 무선 표집하여 총 329명을 대상으로 한 1차 예비 검사와, 만 3 개월부터 17 세 11 개월까지 남녀별로 기준 표집하 여 총 2763 명의 일반 아동, 그리고 3세에서 17세까지 남녀별로 표집한 총 406명의 정신지체 아동을 대상으로 표준화검사를 실시하여 국내 표준화 연구를 마쳤다. 한국판 적응행동검사 $(\mathrm{K}-\mathrm{SIB}-\mathrm{R})$ 의 사용목적은 개인의 적응력 및 특정 환경에서의 기능적 독립성의 정도를 구체화하는 것이다. 이 검사는 학교, 가정, 직장 및 지역 사회에서의 독립과 적응기능을 측정하기 위 해 고안되었다. ${ }^{20)}$ 이 척도는 14 개의 하위척도로 이루어진 259 개의 독립적 적응행동 문항과 8 개의 문제행동 문항으로 나누 어져 있다. 적응행동은 4점 척도(0 3점까지)로 평가하며, 문제 행동은 “예", "아니요"로 답한 후 문제행동이 있을 경우, 빈도 (0 5점까지)와 심각성(0 4점까지)으로 구체적으로 평가하도록 되어있다. 본 연구에서는 K-SIB-R 중 문제행동 소척도를 사 용하였다. 문제행동은 자신을 해치는 행동, 타인을 해치는 행 동, 물건을 파괴하는 행동, 방해하는 행동, 특이한 반복적인 습관, 사회적으로 공격적인 행동, 위축된 행동이나 부주의한 행 동, 비협조적인 행동으로 구성된다. 각 점수에(0 5점/0 4점)
항목에 따라 6 37까지 가중치를 두어 4 개의 문제행동 지수 를 구한다. 문제행동 지수는 내적 문제행동 지수(Internalized Maladaptive Index, IMI), 외적 문제행동 지수(Externalized Maladaptive Index, EMI), 반사회적 문제행동 지수(Asocial Maladaptive Index, AMI), 일반적 부적응 지수(General Maladaptive Index, GMI)로 구성되어 있으며 -70 에서 +10 범위 를 가지는데, -10 이상을 정상으로 평가하고, -10 미만에서는 값이 작을수록 문제행동이 심각한 것으로 평가한다. ${ }^{20)}$ 본 연 구에서는 IMI, EMI, AMI, GMI 4개의 지수 외에도 8개 문제 행동 문항의 심각성과 빈도를 반영한 중간값인 가중 평균을 함께 사용하였고, 값이 클수록 문제행동이 심각한 수준임을 의미한다.

\section{아동 청소년 행동 평가도구(Korean version of the Child}

\section{Behavior Checklist, $\mathrm{K}-\mathrm{CBCL}$ )}

여러 나라에서 널리 사용되고 있는 행동 평정 척도 중 하나 인 아동 청소년 행동 평가척도 $(\mathrm{K}-\mathrm{CBCL})$ 는, 아동 청소년기의 다양한 사회적 적응 및 정서, 행동 문제를 다차원적으로 평정 하는 척도로서, 기초 역학조사 도구일 뿐 아니라, 아동 청소년 의 심리 장애 진단을 위해서도 유용한 도구로 알려져 있다. 국내에서는 Achenbach(1991)가 제작한 CBCL을, 예비연구를 거쳐 한국판 아동 청소년 행동 평가척도 $(\mathrm{K}-\mathrm{CBCL})$ 로 표준화 하였다. ${ }^{21)}$ 한국판 아동 청소년 행동 평가척도는 크게 사회 능 력 척도와 문제행동 증후군 척도로 구성되어 있으며, 사회 능 력 척도는 다시 3 개로 나뉘어 사회 성숙도, 학업 수행 척도, 총 사회 능력 점수로 이루어져 있다. 이 검사 도구는 119 개의 문제 행동에 관한 항목으로 구성되어 있는데, 각 항목은 3점 척도 로 평가되며, 문제행동 증후군 척도는 해당 문제행동 항목들 의 합으로 계산된다. 본 연구에서는 문제행동 증후군 척도의 문제행동 총점, 내재화, 외현화 척도를 사용하였고, T점수 64 점 이상을 임상 범위로 정의한다. 이 세 가지 척도 외에도 불 안/우울, 위축/우울, 신체증상, 사회적 미성숙, 사고 문제, 주의 집중 문제, 규칙 위반, 공격 행동, 기타 문제의 9 개의 소척도를 함께 사용하였고, 소척도들은 T점수 70점 이상을 임상 범위로 정의하였다.

\section{자료의 분석}

연구 대상군과 대조군의 차이 검증을 위해서 t-test를 실시 하였다. BPI-01의 신뢰도 검증하기 위해 내적 일치도를 구하 였는데, 분석은 Cronbach $\alpha$ 계수로 계산하였다. 타당도 검증 을 위해서는 공존 타당도와 변별 타당도를 검증하였다. 공존 타당도는 BPI-01의 소척도와 적응행동검사 $(\mathrm{K}-\mathrm{SIB}-\mathrm{R}) 14$ 개 하위척도 중 문제행동 평가척도 소척도에 해당하는 8 개의 영 
역을 피어슨 상관 분석(Pearson correlation test)을 통해 검 증하였다. 변별 타당도는 BPI-01의 소척도와 아동·청소년 행 동 평가척도 $(\mathrm{K}-\mathrm{CBCL})$ 중 문제행동 증후군 척도를 피어슨 상 관 분석을 통해 검증하였다. 본 연구의 모든 통계분석에는 SPSS ver. 21.0(IBM Corp., Armonk, NY, USA)을 사용하였 고 통계적 유의 수준은 0.05 미만으로 하였다.

\section{결 과}

임상군과 대조군의 인구학적 특성과 임상특징(Table 1)

본 연구에 참여한 아동 141 명 중 대조군은 100 명(연령 $10.90 \pm$ 1.71 , 남아 54명), 임상군은 41명(연령 10.36 \pm 5.21 , 남아 30명) 이었다. 두 군 간에 연령은 $(\mathrm{p}=0.520)$ 유의한 차이가 없었으나, 성별은 $(\mathrm{p}=0.034)$ 임상군의 남아 비율이 유의하게 많았다.

Table 1. Demographic information and clinical characteristics of children

\begin{tabular}{|c|c|c|c|}
\hline & Control $(n=100)$ & Patient $(n=41)$ & $n$ \\
\hline & $M(S D)$ & $M(S D)$ & $r$ \\
\hline Age, years & $10.90(1.71)$ & $10.36(5.21)$ & 0.520 \\
\hline Gender, boys, n (\%) & $54(54)$ & $30(71.4)$ & 0.034 \\
\hline \multicolumn{4}{|l|}{ BPI-01 } \\
\hline Self-injurious behavior (freq.) & $0.54(1.42)$ & $3.26(3.99)$ & 0.001 \\
\hline Self-injurious behavior (sev.) & $0.41(1.18)$ & $3.33(4.83)$ & 0.001 \\
\hline Stereotyped behavior (freq.) & $0.72(2.15)$ & $11.41(11.18)$ & 0.001 \\
\hline Stereotyped behavior (sev.) & $0.67(1.90)$ & $10.26(10.90)$ & 0.001 \\
\hline Aggressive/destructive behavior (freq.) & $0.49(1.36)$ & $4.57(5.29)$ & 0.001 \\
\hline Aggressive/destructive behavior (sev.) & $0.44(1.13)$ & $4.29(6.15)$ & 0.001 \\
\hline \multicolumn{4}{|l|}{ K-SIB-R } \\
\hline IMI & $-1.13(8.84)$ & $-13.18(14.04)$ & 0.001 \\
\hline Hurtful to self & $33.26(5.20)$ & $37.03(6.55)$ & 0.003 \\
\hline Unusual or repetitive habits & $30.40(4.02)$ & $37.87(5.31)$ & 0.001 \\
\hline Withdrawal or inattentive behavior & $12.20(1.76)$ & $37.56(5.94)$ & 0.001 \\
\hline EMI & $14.59(4.92)$ & $4.44(15.00)$ & 0.001 \\
\hline Hurtful to others & $22.86(3.62)$ & $34.49(4.50)$ & 0.001 \\
\hline Destructive to property & $12.47(1.96)$ & $34.23(7.23)$ & 0.001 \\
\hline Disruptive behavior & $21.40(2.89)$ & $34.51(4.91)$ & 0.001 \\
\hline $\mathrm{AMI}$ & $0.10(7.92)$ & $-5.28(11.68)$ & 0.011 \\
\hline Socially offensive behavior & $21.31(3.02)$ & $50.39(6.52)$ & 0.001 \\
\hline Uncooperative behavior & $20.96(2.53)$ & $53.33(5.53)$ & 0.001 \\
\hline GMI & $-1.03(7.00)$ & $-12.69(14.52)$ & 0.001 \\
\hline \multicolumn{4}{|l|}{$\mathrm{K}-\mathrm{CBCL}$} \\
\hline Total problems & $49.63(11.86)$ & $68.75(13.94)$ & 0.001 \\
\hline Internalizing & $50.64(10.28)$ & $62.96(11.63)$ & 0.001 \\
\hline Externalizing & $50.60(10.08)$ & $63.56(12.80)$ & 0.001 \\
\hline Anxious/depressed & $54.21(6.14)$ & $62.00(8.14)$ & 0.001 \\
\hline Withdrawal/depressed & $54.65(6.36)$ & $62.46(8.93)$ & 0.002 \\
\hline Somatic complaints & $54.19(5.82)$ & $55.89(5.77)$ & 0.175 \\
\hline Social problems & $54.10(6.42)$ & $70.30(7.14)$ & 0.001 \\
\hline Thought problems & $54.54(6.17)$ & $65.74(8.49)$ & 0.001 \\
\hline Attention problems & $53.83(6.68)$ & $72.14(12.36)$ & 0.001 \\
\hline Rule-breaking behavior & $55.07(6.29)$ & $62.04(7.25)$ & 0.001 \\
\hline Aggressive behavior & $53.93(6.31)$ & $64.11(9.65)$ & 0.001 \\
\hline Etc. & $54.29(6.08)$ & $62.46(8.93)$ & 0.001 \\
\hline
\end{tabular}

AMI: Asocial Maladaptive Index, BPI-01: Behavior Problems Inventory-01, EMI: Externalized Maladaptive Index, freq.: frequency, GMI: General Maladaptive Index, IMI: Internalized Maladaptive Index, K-CBCL: Korean version of the Child Behavior Checklist, KSIB-R: Korean Scales of Independent Behavior-Revised, M: mean, SD: standard deviation, sev.: severity 
BPI-01의 자해, 상동 행동, 공격적/파괴적 행동, 3 영역 모두 에서 임상군이 대조군보다 문제행동 점수가 유의하게 더 높 았고, K-SIB-R에서도 마찬가지로 전 영역에서 임상군이 대 조군보다 문제행동이 심한 것으로 나타났다. $\mathrm{K}-\mathrm{CBCL}$ 의 경우 신체증상 $(\mathrm{p}=0.175)$ 에서만 통계적으로 유의한 차이가 없었고, 나머지 7개 영역에서 모두 임상군이 대조군보다 문제행동 점 수가 높았다.

\section{신뢰도 검증(Table 2)}

BPI-01의 신뢰도를 검증하기 위해 내적 일치도를(Cronbach's $\alpha$ ) 구한 결과, 총 점수는 대조군에서 0.82 , 임상군에서는 빈도 와 심각성이 각각 $0.91,0.92$ 로 모두 0.7 보다 높아 적절한 내적 일치도를 보였다. 각 세부 영역을 보면 자해 행동이 대조군에

Table 2. Internal consistency (Cronbach's a)

\begin{tabular}{lccc}
\hline \multicolumn{1}{c}{ BPI-01 } & Items (n) & Control & Patient \\
\hline Self-injurious behavior & 14 & & \\
Freq. & & 0.64 & 0.69 \\
Sev. & 24 & 0.65 & 0.67 \\
Stereotyped behavior & & & \\
Freq. & & 0.75 & 0.86 \\
Sev. & 11 & 0.72 & 0.87 \\
Aggressive/destructive behavior & & 0.73 & 0.89 \\
Freq. & & 0.69 & 0.81 \\
Sev. & 49 & & 0.82 \\
Total score & & 0.82 & 0.92 \\
$\quad$ Freq. & & & 0.91 \\
Sev.
\end{tabular}

BPI-01: Behavior Problems Inventory-01, Freq.: frequency, Sev.: severity
서 $0.64,0.65$, 임상군에서 $0.69,0.67$ 이었고, 상동 행동은 대조 군에서 $0.75,0.72$, 임상군에서 $0.86,0.87$, 공격적/파괴적 행동 이 대조군에서 $0.73,0.69$, 임상군에서 $0.89,0.81$ 이었다. 이는 외국에서 시행한 선행 BPI-01 표준화 연구의 신뢰도 검증(자 해, 상동, 공격적 파괴적 행동의 Cronbach's $\alpha$ 가 각각 0.61 , $0.79,0.82$ )과 일치하는 결과이다. ${ }^{10)}$

\section{공존 타당도(Concurrent validity) 검증(Table 3)}

$\mathrm{BPI}-01$ 과 $\mathrm{K}-\mathrm{SIB}-\mathrm{R}$ 의 상관을 분석한 결과 임상군의 대부 분의 영역에서 유의미한 상관을 보여 공존 타당도가 있음을 확인하였다. K-SIB-R의 4개의 부적응 지수는 숫자가 작을수 록 문제행동이 심함을 의미하도록 고안되어 있어 점수가 높 을수록 문제행동이 심한 BPI-01 체계와는 부적 상관 관계를 가지게 된다. 임상군에서 $\mathrm{BPI}-01$ 의 총 점수와 $\mathrm{K}-\mathrm{SIB}-\mathrm{R}$ 의 일 반적 부적응 지수(GMI)는 -0.77 로 높은 부적 상관을 보였고, 내적, 외적 부적응 지수(IMI, -0.58 ; EMI, -0.71), 반사회적 부 적응 지수(AMI, -0.64) 역시 높은 상관성을 보여 BPI-01의 총 점수는 K-SIB-R 4개의 모든 부적응 지수와 유의미한 상관을 보였다. 자해의 경우, BPI-01의 '자해 행동'과 K-SIB-R의 '자 신을 해치는 행동'이 0.76 로 높은 상관관계를 보였다. BPI-01 의 '상동 행동'은 K-SIB-R 중 특이한 '반복적인 습관', '방해하 는 행동', '사회적으로 공격적인 행동'과 임상군에서는 0.48 , $0.57,0.54$ 로 비교적 높은 상관관계를 보인 반면, 대조군에서 는 모두 유의미한 상관 관계를 보이지 않았다. BPI-01의 ‘공격 적/파괴적 행동'의 경우, 임상군에서는 K-SIB-R의 '자신을 해 치는 행동, '타인을 해치는 행동', '물건을 파괴하는 행동'과는 높은 상관 관계를 보였으며(0.69, 0.65, 0.67), '방해하는 행동',

Table 3. Convergent validity: pearson correlations across subscales

\begin{tabular}{|c|c|c|c|c|c|c|c|c|}
\hline \multirow{3}{*}{ K-SIB-R } & \multicolumn{8}{|c|}{ BPI-01 } \\
\hline & \multicolumn{4}{|c|}{ Control } & \multicolumn{4}{|c|}{ Patient } \\
\hline & Total & SIB & SB & $A D$ & Total & SIB & SB & $A D$ \\
\hline GMI & $-0.27^{*}$ & -0.16 & -0.18 & $-0.40^{\dagger}$ & $-0.77^{\dagger}$ & $-0.77^{\dagger}$ & $-0.51^{\dagger}$ & $-0.74^{\dagger}$ \\
\hline IMI & $-0.24^{*}$ & $-0.23^{*}$ & -0.16 & $-0.25^{*}$ & $-0.58^{\dagger}$ & $-0.57^{\dagger}$ & $-0.57^{\dagger}$ & $-0.48^{\dagger}$ \\
\hline Hurtful to self & 0.11 & $0.24^{*}$ & -0.04 & 0.11 & $0.63^{\dagger}$ & $0.76^{\dagger}$ & $0.35^{*}$ & $0.69^{\dagger}$ \\
\hline Unusual/repetitive habits & 0.05 & 0.09 & -0.09 & 0.18 & $0.46^{\dagger}$ & $0.32 *$ & $0.48^{\dagger}$ & 0.27 \\
\hline Withdrawal/inattentive behavior & 0.13 & 0.06 & -0.07 & $0.40^{\dagger}$ & 0.21 & 0.10 & 0.28 & 0.03 \\
\hline EMl & -0.10 & 0.01 & 0.07 & $-0.33^{\dagger}$ & $-0.71^{*}$ & $-0.75^{\dagger}$ & $-0.47^{\dagger}$ & $-0.78^{\dagger}$ \\
\hline Hurtful to others & 0.11 & $0.24^{*}$ & -0.03 & 0.10 & $0.50^{\dagger}$ & $0.54^{\dagger}$ & 0.26 & $0.65^{\dagger}$ \\
\hline Destructive to property & 0.11 & $0.25^{*}$ & -0.05 & 0.12 & $0.58^{\dagger}$ & $0.67^{\dagger}$ & 0.31 & $0.67^{\dagger}$ \\
\hline Disruptive behavior & 0.21 & 0.16 & -0.08 & 0.01 & $0.60^{\dagger}$ & $0.47^{\dagger}$ & $0.57^{\dagger}$ & $0.39 *$ \\
\hline AMl & $-0.42^{*}$ & -0.12 & -0.18 & $-0.47^{\dagger}$ & $-0.64^{\dagger}$ & $-0.53^{\dagger}$ & $-0.39 *$ & $0.51^{\dagger}$ \\
\hline Socially offensive behavior & 0.13 & 0.07 & -0.07 & $0.38^{\dagger}$ & $0.61^{\dagger}$ & $0.51^{\dagger}$ & $0.54^{\dagger}$ & $0.44^{\dagger}$ \\
\hline Uncooperative behavior & 0.10 & 0.04 & -0.11 & 0.16 & $0.52^{\dagger}$ & $0.46^{\dagger}$ & $0.45^{\dagger}$ & $0.38^{*}$ \\
\hline
\end{tabular}

${ }^{*} p<0.05,{ }^{\dagger} p<0.01$. AD: aggressive/destructive behavior, AMI: Asocial Maladaptive Index, BPI-01: Behavior Problems Inventory-01, EMI: Externalized Maladaptive Index, GMI: General Maladaptive Index, IMI: Internalized Maladaptive Index, K-SIB-R: Korean Scales of Independent Behavior-Revised, SB: streotyped behavior, SIB: self-injurious behavior 
'사회적으로 공격적인 행동, '비협조적인 행동'(0.39, 0.44, 0.38) 은 중등도 상관 관계를 보였다. 이와 달리 대조군에서는 BPI01의 '공격적/파괴적 행동'이 K-SIB-R의 '위축된 행동이나 부 주의한 행동', '사회적으로 공격적인 행동' $(0.40,0.38)$ 과 유의미 한 상관 관계를 보였다. K-SIB-R의 '위축된 행동이나 부주의 한 행동은 K-SIB-R의 8개 문제행동 영역 중 유일하게 임상군 에서 $\mathrm{BPI}-01$ 의 모든 소영역과(자해, 상동 행동, 파괴/공격적 행 동) 상관관계를 보이지 않았다. 하지만, 대조군에서는 이 항목이 $\mathrm{BPI}-01$ 의 '공격적/파괴적 행동'과 상관성을 $(\mathrm{r}=0.40)$ 보였다.

\section{변별 타당도(Discriminant validity) 검증(Table 4)}

$\mathrm{BPI}-01$ 과 $\mathrm{K}-\mathrm{CBCL}$ 의 상관을 분석한 결과 임상군의 일부 영 역에서 낮은 상관을 보이거나, 유의미하지 않은 상관을 보여 변별 타당도가 있음을 확인하였다. 대조군에서는 전반적으로 낮은 상관도를 보이거나, 유의미한 상관관계를 보이지 않았다. $\mathrm{K}-\mathrm{CBCL}$ 의 세부영역을 보면 '불안/우울, '위축/우울'이 BPI-01 과 변별력이 있는 것으로 보였다. 임상군에서 '불안/우울은 ‘자 해, '상동 행동', ‘공격적/파괴적 행동' 모두와(0.37, 0.26, 0.27) 유의미한 상관을 보이지 않았다. '위축/우울'은 BPI-01의 '상동 행동과는 중등도 상관관계(0.44)를 보였으나, '자해', '공격적/ 파괴적 행동' $(0.25,0.07)$ 과는 유의미한 상관을 보이지 않았다. $\mathrm{K}-\mathrm{CBCL}$ 의 '사회적 미성숙'은 $\mathrm{BPI}-01$ 의 '자해'와 상관성은 있 었으나(0.58), '상동 행동'이나 '공격적/파괴적 행동과의 유의미 한 상관은 보이지 않았다 $(0.21,0.36)$. 임상군에서 $\mathrm{BPI}-01$ 의 상 동 행동은, 다른 소척도 점수들이 $\mathrm{K}-\mathrm{CBCL}$ 의 외현화 척도와 유의미한 상관관계를 가지는 것과 대조적으로 외현화 척도와 유의미한 상관관계를 보이지 않았다. 또한, $\mathrm{K}-\mathrm{CBCL}$ 의 소척도
와의 상관 분석에서도 '불안/우울, '사회적 미성숙, '규칙위반', '공격행동'과 유의미한 상관 관계를 보이지 않았다. BPI-01의 '공격적/파괴적 행동'은 '신체증상', '규칙위반', '공격행동', '주의 집중문제'과 상관관계는 보였지만, '불안/우울, '위축/우울, '사 회적 미성숙, '사고문제와의 유의미한 상관성은 보이지 않았다.

\section{고 찰}

본 연구에서 BPI-01이 발달 장애의 문제행동을 평가하기 위 해 사용할 수 있는 신뢰도와 타당도를 갖고 있는지를 살펴본 결과, 우선 내적 일치도를 통해 본 신뢰도는 만족할 만한 수 준이었다. 임상군-대조군의 평균 비교에서도 임상군의 점수 가 유의하게 높게 나옴으로써 BPI-01이 발달 장애의 문제행 동 평가에 유용하게 쓰일 수 있을 것으로 기대된다.

기존의 상용화된 검사도구인 K-SIB-R과의 상관 분석을 통 해 공존 타당도를 검증한 결과, 임상군 검사 결과의 대부분 영역에서 상관이 유의미하였다. 이는 BPI-01이 발달 장애의 문 제행동을 타당하게 평가하고 있음을 의미한다. BPI-01의 총점 이 K-SIB-R의 일반적 부적응 지수(GMI)와 높은 상관관계를 보인 것으로 볼 때, 문제행동의 전반적인 심각성을 적절히 평 가하고 있는 것으로 보이며, BPI-01의 총점이 내적, 외적, 반사 회적 부적응 지수 중 특히 '외적 부적응 지수'와 상관 관계가 높다는 결과는 BPI-01 점수가 특히 외현화 문제와 연관성이 높음을 의미한다. BPI-01 소척도별로 보면, '자해 행동' 소척도 가 $\mathrm{K}-\mathrm{SIB}-\mathrm{R}$ 의 자해 영역과 높은 상관관계를 보이며 타당도 가 있음을 보여주었고, ‘공격적/파괴적 행동’ 소척도 역시 K-SIB$\mathrm{R}$ 의 외적 부적응행동 중 '타해', '파괴’와 높은 상관 관계를 보

Table 4. Discriminant validity: pearson correlations across subscales

\begin{tabular}{|c|c|c|c|c|c|c|c|c|}
\hline \multirow{3}{*}{$\mathrm{K}-\mathrm{CBCL}$} & \multicolumn{8}{|c|}{ BPI-01 } \\
\hline & \multicolumn{4}{|c|}{ Control } & \multicolumn{4}{|c|}{ Patient } \\
\hline & Total & SIB & SB & $A D$ & Total & SIB & SB & $A D$ \\
\hline Total problems & $0.33^{\dagger}$ & $0.30^{\dagger}$ & $0.25^{*}$ & $0.25^{*}$ & $0.66^{\dagger}$ & $0.58^{\dagger}$ & $0.53^{\dagger}$ & $0.44^{*}$ \\
\hline Internalizing & $0.26^{\dagger}$ & 0.16 & $0.23 *$ & $0.23^{*}$ & $0.57^{\dagger}$ & $0.48^{\dagger}$ & $0.46^{*}$ & $0.39 *$ \\
\hline Externalizing & $0.25^{*}$ & $0.22 *$ & 0.18 & $0.20 *$ & $0.61^{\dagger}$ & $0.70^{\dagger}$ & 0.36 & $0.52^{\dagger}$ \\
\hline Anxious/depressed & $0.21^{*}$ & 0.13 & 0.16 & $0.22 *$ & 0.36 & 0.37 & 0.26 & 0.27 \\
\hline Withdrawal/depressed & 0.19 & 0.12 & 0.17 & 0.15 & $0.39 *$ & 0.25 & $0.44^{*}$ & 0.07 \\
\hline Somatic complaints & $0.29^{\dagger}$ & $0.20 *$ & $0.27^{\dagger}$ & 0.19 & $0.73^{\dagger}$ & $0.73^{\dagger}$ & $0.49^{\dagger}$ & $0.61^{\dagger}$ \\
\hline Social problems & $0.37^{\dagger}$ & $0.35^{\dagger}$ & $0.28^{\dagger}$ & $0.26^{\dagger}$ & $0.42^{*}$ & $0.58^{\dagger}$ & 0.21 & 0.36 \\
\hline Thought problems & $0.24^{*}$ & $0.24^{*}$ & 0.17 & 0.18 & $0.61^{\dagger}$ & $0.45^{*}$ & $0.56^{\dagger}$ & 0.33 \\
\hline Attention problems & $0.31^{\dagger}$ & $0.32^{\dagger}$ & $0.24^{*}$ & 0.18 & $0.70^{\dagger}$ & $0.61^{\dagger}$ & $0.58^{\dagger}$ & $0.44^{*}$ \\
\hline Rule-breaking behavior & $0.25^{*}$ & $0.22^{*}$ & 0.18 & $0.21^{*}$ & $0.59^{\dagger}$ & $0.63^{\dagger}$ & 0.40 & $0.43^{*}$ \\
\hline Aggressive behavior & 0.16 & 0.15 & 0.10 & 0.14 & $0.56^{+}$ & $0.67^{\dagger}$ & 0.32 & $0.49^{\dagger}$ \\
\hline Etc. & $0.31^{\dagger}$ & $0.35^{\dagger}$ & $0.26^{\dagger}$ & 0.11 & $0.58^{+}$ & $0.47^{*}$ & $0.53^{\dagger}$ & 0.29 \\
\hline
\end{tabular}

${ }^{*} p<0.05,{ }^{\dagger} p<0.01$. AD: aggressive/destructive behavior, BPI-01: Behavior Problems Inventory-01, K-CBCL: Korean version of the Child Behavior Checklist, SB: stereotyped behavior, SIB: self-injurious behavior 
임으로써 공격/파괴 행동 문제를 타당하게 평가하고 있음을 알 수 있었다. 이 두 소척도와 달리 '상동 행동 소척도는 K-SIB$\mathrm{R}$ 의 상동 행동 평가 영역에 해당하는 '특이한 반복적인 습관' 과 중등도 상관 관계를 보이면서, 동시에 ‘방해나 비협조, 사회 적으로 공격적인 행동과도 비교적 높은 상관 관계를 보였다. 이는 BPI-01에서 상동 행동으로 분류하는 행동 문제(예: 사 물의 냄새를 가까이 가서 맡는 행동, 고함치고 비명을 지르는 행동, 이리저리 뛰어다니는 행동, 손뼉 치는 행동, 신체를 비비 거나 문지르는 행동)를 $\mathrm{K}-\mathrm{SIB}-\mathrm{R}$ 에서는 발달 장애의 핵심 증 상으로 평가하기보다는 사회적인 맥락에서 해석하여 불쾌한 행동(socially offensive behavior, 예: 타인에게 너무 가까이 접근하거나 만지는 행동, 성기 만지기)이나 방해(예: 이유없이 웃거나 울기, 고함치거나 악쓰기)로 분류하였기 때문일 수 있 다. 본 연구에서는 $\mathrm{BPI}-01$ 과 $\mathrm{K}-\mathrm{SIB}-\mathrm{R}$ 의 상관 관계를 각 항 목별로 분석하지 않았으므로 이 주제는 향후 연구에서 다루 어 볼 수 있겠다.

변별 타당도를 검증하기 위해 $\mathrm{BPI}-01$ 을 $\mathrm{K}-\mathrm{CBCL}$ 과 상관 분석한 결과, 전반적으로 우울, 불안, 위축과 같은 정서 문제 와 관련된 영역에서 변별 타당도가 높은 것으로 나타났고, BPI-01 소척도에서 본다면 '상동 행동'과 '공격적/파괴적 행동' 소척도 영역이 자해 행동 소척도보다 변별 타당도가 높았다. 임상군의 자해와 타해 행동은 $\mathrm{CBCL}$ 의 불안, 우울, 위축과 상 관관계가 유의미하지 않은 것으로 나타나, $\mathrm{K}-\mathrm{CBCL}$ 이 평가하 는 정서·행동 문제와 $\mathrm{BPI}-01$ 이 평가하는 자타해 문제는 성질 이 다를 수 있음을 의미한다. BPI-01의 상동 행동 소척도의 경우 다른 소척도와 달리, $\mathrm{K}-\mathrm{CBCL}$ 의 외현화 척도와 상관 관 계를 보이지 않았을 뿐만 아니라 공격 행동, 규칙 위반, 사회적 미성숙과도 상관을 보이지 않았다. 이는 상동 행동이 $\mathrm{K}-\mathrm{CBCL}$ 이 측정하는 사회적인 미성숙이나 공격성과는 다른 성질의 문 제행동임을 의미하며, BPI-01에서 평가하는 발달 장애의 상 동 행동(고함치고 비명을 지르는 행동, 이리저리 뛰어다니는 행동, 신체를 비비거나 문지르는 행동, 기괴한 자세를 유지하 는 행동 등)은 사회적인 맥락에서 평가하기보다는 발달 장애 의 고유 증상으로서 평가할 필요가 있음을 시사한다. ${ }^{22)} \mathrm{BPI}-$ 01 의 3 개 소척도 중 상동 행동 소척도는 상동 행동에 잘 검증 된 척도로, 원래 지적 장애의 상동 행동을 평가하기 위해 따 로 개발되었으며, 나중에 나머지 두 척도에 통합되었다. ${ }^{22)}$ 본 연 구에서 $\mathrm{K}-\mathrm{SIB}-\mathrm{R}, \mathrm{K}-\mathrm{CBCL}$ 과의 타당도 검증을 통해 볼 때에 도, $\mathrm{BPI}-01$ 이 자해, 공격적/파괴적 행동뿐 아니라 발달 장애 의 상동 행동 평가에 특히 유리할 수 있음을 알 수 있다.

선행 한국판 BPI-01 표준화 연구 ${ }^{18)}$ 는 시설 거주 발달 장애 성인을 대상으로 하였다. 그러나 집에서 양육하는 발달 장애 환자의 경우 주로 소아기나 청소년기에 문제행동이 문제가 되
는 경우가 대부분이라 연구 대상 연령군에 제한점이 있었다. 본 연구는 소아청소년을 대상으로 하였고, 일반 인구와 병원을 내원할 정도로 문제행동이 심한 임상군을 비교하여 선행 연 구의 제한점을 보완할 수 있었다. 하지만, 임상군에 자폐 스펙 트럼 장애 아동만 포함이 되어 지적 장애에 대한 평가가 제한 되었으므로, 연구 결과를 발달 장애 아동 전반으로 일반화하 는데는 한계가 있을 수 있다. 또, 지능 지수나 자폐 척도와 같 이 임상군이 가지고 있는 질환의 심각도나 문제행동의 정도에 대한 정보가 파악되지 않아 임상군의 임상적 특징에 대한 파악 이 제한적이라는 한계가 있다.

\section{결 론}

본 연구에서 검증한 한국형 $\mathrm{BPI}-01$ 은 외국 선행 표준화 연 구 $^{10)}$ 와 일치하는 신뢰도를 가지며, 공존 타당도 분석에서 전 반적인 문제행동 심각도뿐 아니라, 자해 행동, 상동 행동, 공격 적/파괴적 행동의 3 가지 소척도도 각 문제행동 영역을 타당하 게 측정할 수 있는 검사 도구임을 검증하였다. 또한, 변별 타 당도 분석을 통해 기존의 검사도구와 $\mathrm{BPI}-01$ 이 문제행동을 차별성 있게 평가하는지 검증하였는데, BPI-01은 정서 문제 와 상관성을 낮게 보이며 특히 상동 행동 소척도에서 변별력 을 보여 발달 장애의 문제행동에 더 유리한 검사일 가능성을 보였다.

중심 단어:문제행동; 자폐 스펙트럼 장애; 문제행동 평가도구.

\section{Acknowledgments}

This work was supported by Ministry of Health and Welfare (grant number HI14C1098) and Seoul National Hospital (project number 2014-31).

\section{Conflicts of Interest}

The authors have no financial conflicts of interest.

\section{REFERENCES}

1) Statistics Korea. The number of registered disabled persons [cited 2016 Dec 15]. Available from: http://kosis.kr/common/meta onedepth.jsp?vwcd=MT_OTITLE\&listid=101_11761.

2) Fombonne E. Thimerosal disappears but autism remains. Arch Gen Psychiatry 2008;65:15-16.

3) Kim YS, Leventhal BL, Koh YJ, Fombonne E, Laska E, Lim EC, et al. Prevalence of autism spectrum disorders in a total population sample. Am J Psychiatry 2011;168:904-912.

4) Jung KM. Effectiveness of behavioral parent training program for children with developmental disabilities and PDD. Proceeding of the Korean Psychologial Assocoaition Annual Conference;2008 Aug 20;Seoul, Korea. Seoul: Korean Psychologial Assocoaition;2008. p.560-561.

5) Fitzpatrick SE, Srivorakiat L, Wink LK, Pedapati EV, Erickson CA. Aggression in autism spectrum disorder: presentation and treatment options. Neuropsychiatr Dis Treat 2016;12:1525-1538. 
6) Simonoff E, Pickles A, Charman T, Chandler S, Loucas T, Baird G. Psychiatric disorders in children with autism spectrum disorders: prevalence, comorbidity, and associated factors in a population-derived sample. J Am Acad Child Adolesc Psychiatry 2008;47:921-929.

7) Campbell SB. Behavior problems in preschool children: a review of recent research. J Child Psychol Psychiatry 1995;36:113-149.

8) Lecavalier L. Behavioral and emotional problems in young people with pervasive developmental disorders: relative prevalence, effects of subject characteristics, and empirical classification. J Autism Dev Disord 2006;36:1101-1114.

9) Yoo SO. Analyzing the research trends on prevention and intervention of challenging behaviors of young children with disabilities in Korea. Spec Educ Res Inst 2015;14:255-279.

10) Rojahn J, Schroeder SR, Mayo-Ortega L, Oyama-Ganiko R, LeBlanc J, Marquis J, et al. Validity and reliability of the Behavior Problems Inventory, the Aberrant Behavior Checklist, and the Repetitive Behavior Scale-Revised among infants and toddlers at risk for intellectual or developmental disabilities: a multi-method assessment approach. Res Dev Disabil 2013;34:1804-1814.

11) Kim YL, Kim NH, Park JY. The effects of problem behavior of students with disabilities on their family life and families' coping styles: a qualitative inquiry. J Emot Behav Disord 2010;26:17-43.

12) Hastings RP, Daley D, Burns C, Beck A. Maternal distress and expressed emotion: cross-sectional and longitudinal relationships with behavior problems of children with intellectual disabilities. Am J Ment Retard 2006;111:48-61.

13) Kwon SJ. A study on the factors affecting extra cost of disabled children. GRI Rev 2014;16:271-291.

14) Yoon MS. Seoul Institute policy report: research on services and policies for adults with developmental disability in Seoul. Seoul: The Seoul Institute;2013. p.1-17.
15) Shin YH, Park JH, Choi MH, Lee HS. The study on staff needs for executing positive behavioral support through an investigation on challenging behavioral problems of children with developmental disabilities at nursery school level. J Emot Behav Disord 2008;24:337352.

16) Rojahn J, Matson JL, Lott D, Esbensen AJ, Smalls Y. The Behavior Problems Inventory: an instrument for the assessment of self-injury, stereotyped behavior, and aggression/destruction in individuals with developmental disabilities. J Autism Dev Disord 2001;31:577588.

17) Jeong B, Yoo E, Jung M, Kang D, Park S, Park SH. Validity and reliability of the Korean version of the behaviour problems inventory. J Appl Res Intellect Disabil 2013;26:578-590.

18) Bang SY, Lee JW, Hwang SH, Hong EJ, Park JH. Development of tools and protocols assessing problematic behaviors in children with developmental disorder [cited 2016 Dec 30]. Available from: http://

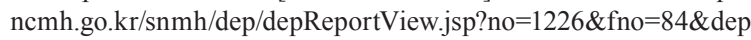
$\operatorname{art}=0 \&$ search_gubun $=1 \& p g=3 \&$ search_item $=0 \&$ search_content $=$ \&menu_cd=M_05_07_00_00_00

19) Paik EH, Lee BI, Cho SJ. Korean Scales of Independent BehaviorRevised (K-SIB-R). Seoul: Hakjisa psychology reseach institute; 2007.

20) Pyeon DW, Baek JN, Kim CH, Park MH, Choi YN, Wongu E. The verification of validity of K-SIB-R (Korean-Scales of Independent Behavior-Revised). J Emot Behav Disord 2009;25:1-15.

21) Oh KJ, Lee HR, Hong KE, Ha EH. K-CBCL Korean version of the Child Behavior Checklist. Seoul: Jungang Aptitude Research Institute; 1997.

22) Rojahn J, Matlock ST, Tassé MJ. The stereotyped behavior scale: psychometric properties and norms. Res Dev Disabil 2000;21:437454. 